\title{
DESKRIPSI MORFOLOGI JENIS ULAR DAN KATAK PADA KAWASAN HUTAN PULAU MANSINAM
}

\section{(Morphological Description of Snake and Frog Species in the Forested Area of Mansinam Island)}

\author{
Tirza Abaire ${ }^{1}$ dan Meliza S. Worabai ${ }^{1 凶}$ \\ Jurusan Kehutanan, Fakultas Kehutanan Universitas Papua Manokwari, Papua Barat, \\ 98314. Tlp/Fax: +62986211065. \\ $\bowtie$ Penulis Korespondensi: Email: meliza wrb@yahoo.com \\ Diterima: 8 Feb 2018| Disetujui: 2 Mar 2018
}

\begin{abstract}
Abstrak
Penelitian ini dilakukan pada kawasan hutan Pulau Mansinam selama satu minggu dengan tujuan untuk mengetahui morfologi ular dan katak yang ditemukan. Metode yang digunakan dalam penelitian ini ialah metode deskriptif dan teknik observasi lapang dan penemuan secara langsung dari jenis yang diteliti. Hasil penelitian ini menunjukan terdapat 3 jenis ular dan 3 jenis katak yang ditemukan pada kawasan hutan Pulau Mansinam. Jenisjenis tersebut ialah 3 dari kelas reptil: Laticauda colubrina, dari famili hydrophiidae, Stegonotus cuculatus dari famili colubridae, Candoia sp. dari famili boidae dan 3 dari kelas amfibi; Litoria infrafernata dari famili hylidae, Rana sp.dan platmantis papuaensis dari famili ranidae.
\end{abstract}

Kata kunci: Deskripsi morfologi, amfibi, reptil, kawasan hutan, Pulau Mansinam.

\begin{abstract}
This study has been carried out in forested area of Mansinam Island with duration of one week in order to determine morphological attributes of snake and frog species found. Method that applied in the study was descriptive through field observation technique by directly identifying objects during fiend walking across the island. The result pointed out that there were three species of snakes and another three species of frogs in the island. These species then elaborated into: three species came from reptile class: Laticauda colubrina, from hydrophiidae family, Stegonotus cuculatus from the family of colubridae, Candoia $s p$. from the family of boidae and three were from amphibian class; Litoria infrafernata from the family of hylidae, Rana sp. and platmantis papuaensis from the familyi of ranidae.
\end{abstract}

Keywords: Morphological description, amphibian, reptile, forest area, Mansinam Island.

\section{PENDAHULUAN}

Indonesia merupakan negara kepulauan yang terdiri dari 17.000 pulau dengan ukuran yang bervariasi serta dengan komposisi tumbuhan dan hewan yang kompleks. Berdasarkan endemisitasnya, invertebrata merupakan salah satu pusat keanekaragaman hayati yang tersebar di dunia (Iskandar dan Erdelen 2006). BAPPENAS (1993) menyatakan bahwa $16 \%$ dari jumlah amfibi dan reptil di dunia terdapat di 
Indonesia dengan jumlah lebih dari 1.100 jenis. Herpeofauna adalah kelompok fauna yang terdiri dari reptil dan amfibi yang berasal dari kata herpeton yang berarti binatang melata. Dengan adanya perkembangan ilmu taksonomi yang terus berkembang maju, reptil dan amfibi dimasukan ke dalam satu kelompok hewan melata. Namun seiring berkembangnya ilmu pengetahuan khususnya ilmu tentang biologi akhirnya di pisahkan menjadi dua kelompok. Kedua kelompok ini di masukan ke dalam bidang ilmu herpetologi karena mempunyai cara hidup yang serupa, sama-sama satwa vertebrata eksoternal (membutuhkan suhu panas ekternal). Reptil maupun amfibi dapat ditemukan mulai dari dataran rendah sampai pada dataran tinggi. Amfibi tidak ditemukan dilaut sedangkan reptil dapat ditemukan pada lautan (Alonso et al. 2000).

Salah satu kelompok reptil yang sangat dikenal adalah ular yang di klasifikasikan ke dalam ordo Squamata, Sub-ordo invertebrata (Ophidia). Saat ini di seluruh dunia terdapat 2500-2700 spesies ular dengan 414 genus dan 13 famili. Ular terdistribusi di seluruh permukaan bumi kecuali daerah Artik, Islandia, Selandia Baru, dan beberapa Pulau kecil di lautan luas (Obst et al.1988). Keberadaan reptil pada suatu ekosistem memberikan peranan dalam suatu mata rantai untuk menjaga keseimbangan ekosistem, karena reptil merupakan karnifora pada rantai makanan. Saat ini reptil mengalami penurunan populasi dalam skala global dan terdapat lima ancaman yang signifikan dalam mempengaruhi kepunahan reptil yaitu kehilangan habitat, degradasi, introduksi, polusi lingkungan, penyakit, dan perubahan iklim global (Gibbons et al. 2000).

Amfibi merupakan salah satu komponen penyusun ekosistem yang memiliki peranan sangat penting, baik secara ekologis maupun ekonomis. Secara ekologis, amfibi berperan sebagai pemangsa konsumen primer seperti serangga atau hewan invertebrata lainnya (Iskandar 1998). Serta dapat digunakan sebagai bio-indikator kondisi lingkungan (Stebbin \& Cohen 1997). Indonesia memiliki dua dari tiga ordo amfibi yang ada di dunia yaitu Gymnophiona dan Anura. Ordo Gymnophiona dianggap langkah dan sulit diketahui keberadaannya, sedangkan ordo Anura merupakan yang paling mudah ditemukan di Indonesia sekitar 450 jenis atau 11\% dari seluruh jenis anura di dunia. ordo Caudata merupakan satu - satunya ordo yang tidak ditemukan di Indonesia (Iskandar 1998).

Papua merupakan provinsi terbesar di Indonesia seluas $416.000 \mathrm{~km}^{2}$ yang menempati bagian Barat New Guinea adalah pulau tropis terbesar dan terkaya di Indonesia. New Guinea merupakan permata diantara pulau-pulau katulistiwa dengan keanekaragaman hayati yang tinggi dan unik, sebagian besar spesies yang ditemukan pada pulau ini bersifat endemik. Menurut lokakarya konservasi keanekaragaman hayati Irian Jaya (Sekarang Papua) di Jayapura, tahun 2000 menyebutkan bahwa Papua memiliki 20.000-25.000 spesies tumbuhan berkayu; 164 spesies mamalia; 329 spesies reptil dan amfibim 650 spesies burung; 250 spesies ikan air tawar; 150 . 000 spesies serangga; dan beratus ratus invertebrata air tawar. Sampai saat ini paling sedikit ada 231 spesies reptil yang telah diketahui dari Papua (Conservation 
International 2000). Reptil yang terdapat di Papua terdiri dari tiga ordo yaitu: ordo squamata (kadal dan ular), testudinata (kura-kura dan penyu), dan crocodilia (buaya). Tercatat kadal di Papua berjumlah 141 jenis, ular 83 jenis, kurakura dan penyu 15 jenis dan buaya 2 jenis (Dumutu 2010). Penelitian ini bertujuan untuk mengetahui morfologi ular dan katak yang ditemukan pada kawasan hutan Pulau Mansinam.

\section{METODE PENELITIAN}

Penelitian ini dilaksanakan pada kawasan hutan Pulau Mansinam, Kabupaten Manokwari yang berlangsung selama 2 bulan yakni bulan Mei s/d Juni 2015 (1 minggu kegiatan pengamatan langsung di lapangan dan selanjutnya pengolahan data lapangan) dengan metode deskriptif yaitu melalui satu teknik pengambilan yakni teknik Visual Encounter Survey (VES) atau teknik survei perjumpaan visual (Conservation International 2000). Metode ini dilakukan secara diurnal dan nokturnal yaitu pengamatan pada siang serta malam melalui jalur transek pengamatan. Dalam penelitian ini variabel yang diamati meliputi deskripsi morfologi jenis ular dan katak. Morfologi ular dan katak yang diamati meliputi warna tubuh dan panjang tubuh dari masing-masing jenis.

\section{Prosedur Penelitian}

\section{A. Persiapan}

Persiapan awal yang dilakukan sebelum melakukan pengamatan, yaitu menentukan lokasi pengamatan dengan menggunakan GPS, kemudian pada lokasi yang telah di tetapkan, dilakukan pembuatan transek pegamatan sepanjang $1 \mathrm{~km}$ pada siang hari sebagai jalur pengumpulan data.
B. Proses Pengumpulan Data

Waktu pengamatan

serta

pengumpulan sampel reptil dilakukan dua kali dalam satu hari yaitu pada siang hari pukul 09.00 - 12.00 WIT dan pada malam hari pukul 17.00- 22.00 WIT. Pengamatan yang dilakukan yaitu sepanjang jalur transek dan jenis yang ditemukan selanjutnya langsung didata. Untuk jenis ular ditangkap dengan mengunakan kayu bercabang seperti huruf $\mathrm{Y}$ sedangkan katak ditangkap menggunakan sarung tangan. Jenis ular dan katak yang besar ditangkap dan dimasukan ke dalam kantung spesimen yang telah diberi nomor/label spesimen. Setelah itu dilakukan pencatatan tipe dan kondisi habitat serta suhu dan keadaan cuaca.

C. Pembuatan Spesimen

Jenis reptil dan amfibi yang ditemukan, sebelum dilakukan pembuatan spesimen terlebih dahulu difoto. Setalah itu spesimen dibuat guna proses identifikasi lanjutan. Pembuatan spesimen dibuat dalam bentuk spesimen basah. Pembuatan spesimen basah dilakukan untuk jenis reptil yang berukuran kecil atau ular.

D. Preservasi

Preservasi (pembiusan) dengan cara memasukan jenis reptil dan amfibi kedalam wadah yang berisikan cairan chlorobutanol, khsusnya untuk jenis reptil yang berukuran kecil sedangkan untuk jenis reptil dan amfibi yang berukuran besar di suntik dengan mengunakan alkohol 70\%.

\section{Analisis Data}

Data yang di peroleh dari hasil penelitian dianalisis secara deskriptif dan disajikan dalam bentuk tabel dan gambar. 


\section{HASIL DAN PEMBAHASAN}

\section{Jenis Yang Ditemukan}

Dari hasil penelitian yang dilakukan di Pulau Mansinam, selanjutnya didata enam jenis amfibi dan reptil. Keenam Tabel 1. Jenis-jenis ular dan katak yang ditemukan di lokasi pengamatam Pulau Mansinam

\begin{tabular}{llllc}
\hline Kelas & Ordo & Famili & Spesies & Jumlah \\
\hline Amfibi & Anura & Hylidae & L. infrafrenata & 8 \\
& & Ranidae & Rana sp. & 16 \\
& & & P. papuensis & 12 \\
\hline Reptil & \multirow{2}{*}{ Squamata } & Hydrophiidae & L. Colubrina & 2 \\
& & Colubridae & S. Cuculatus & 2 \\
& & Boidae & Candoia sp. & 1 \\
\hline Jumlah & 2 & & \multicolumn{2}{c}{6} \\
\hline
\end{tabular}

Dapat dilihat bahwa dari tiga jenis amfibi yang ditemukan terdiri dari dua famili yaitu Hylidae dan Ranidae. Sementara reptil yang ditemukan terdiri dari tiga famili yaitu, Hydrophiidae, Colubridae dan Boidae. Dari keenam spesies yang ditemukan, individu yang paling banyak adalah berasal dari jenis Rana sp. yang merupkan kelas amfibi. Sedangkan jenis yang paling sedikit ditemukan adalah spesies Candoia sp. dari kelas reptil. Hal tersebut kemungkinan disebabkan kurangnya waktu pengamatan yang dilakukan dimana jika pengamatan dilakukan lebih lama, kemungkinan akan ditemukan hasil yang berbeda, karena habitat di Pulau Mansinam sangat mendukung keberadaan spesies reptil.

\section{Deskripsi Karakteristik Morfologi Jenis Reptil dan Amfibi Yang Ditemukan}

A. Reptil (Ular)

Reptil adalah hewan bertulang belakang yang bersisik dan bernapas jenis tersebut masing-masing terdiri dari tiga spesies amfibi dan tiga jenis reptil. Data amfibi dan reptil di kawasan hutan Pulau Manisnam dapat dilihat pada tabel 1. 

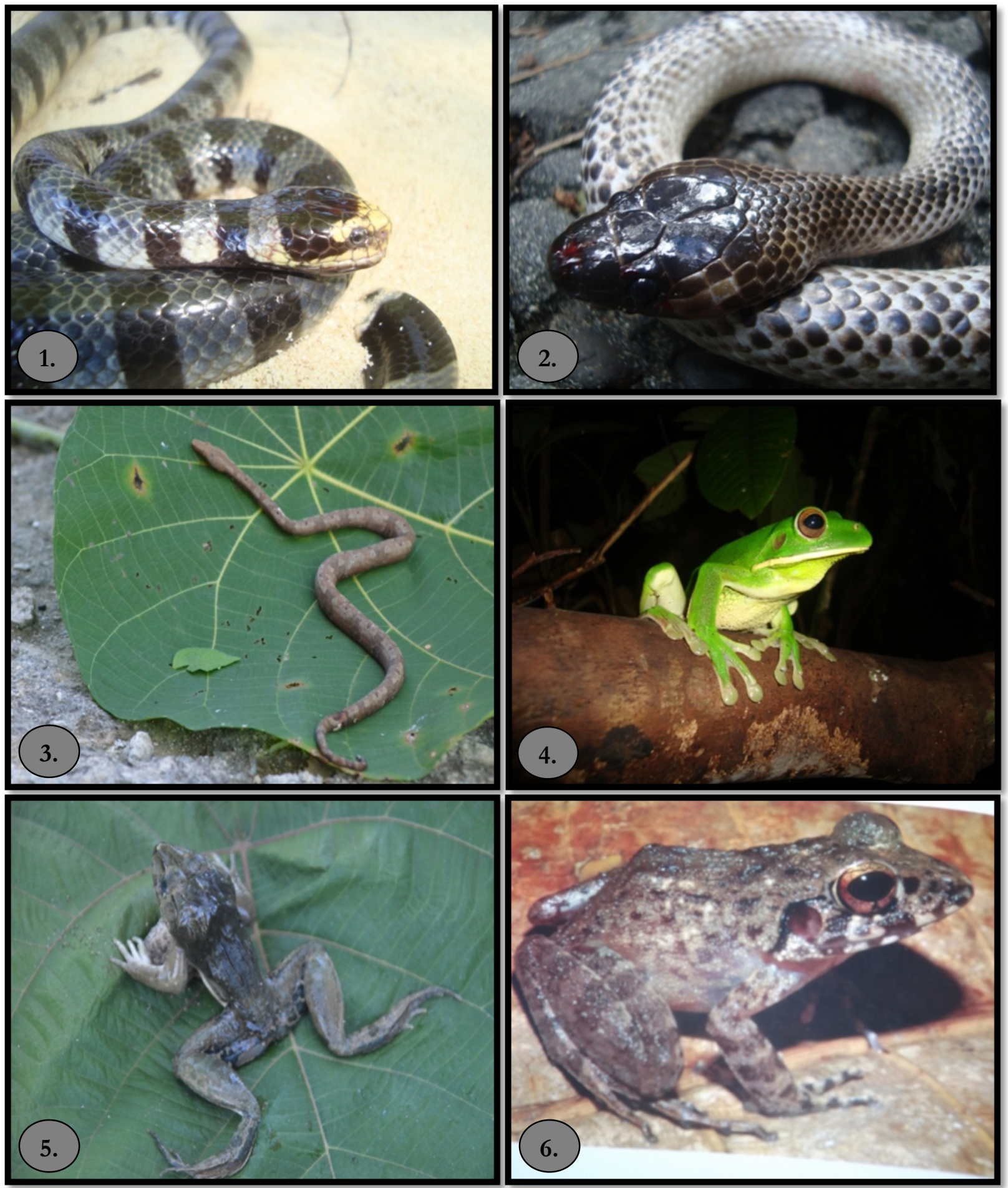

Gambar 1. Jenis-jenis amfibi dan reptil yang ditemukan pada kawasan hutan Pulau Mansinam: 1). jenis .Laticauda colubrine; 2). jenis Stegonotus cuculatus; 3). jenis Candoia sp.; 4). jenis Litoria infrafernata; 5). jenis Rana sp.; 6). jenis Platymantis papuensis. 
Jenis makanan yang dikonsumsi berasal dari laut yaitu ikan dan kerang. Panjang tubuh ular ini \pm 58 $\mathrm{cm}$ dan umumnya ular ini memiliki bentuk tubuh yang pipih, dan segi. Lubang hidung berkatup pada ujung atas moncong, serta memiliki bentuk kepala seperti kerucut (O’Shea 1996).

2. Famili Colubridae

Stegonotus cuculatus memiliki warna pangkal sisik tubuh ventral putih sampai hitam mengkilap pada ujung sisik. Sementara pada bagian kepala sisik berwarna hitam mengkilap. Pada bagian dorsal sisik berwarna putih.

Stegonotus cuculatus ditemukan pada saat pengamatan malam, dimana pada saat ditemukan berada di pinggiran banir pohon, tepatnya di atas serasah di lantai hutan. Spesies ini merupakan kelompok ular yang berbisa, makanannya berupa katak dan kadal. Panjang tubuh jenis ini ular ini $\pm 70,9 \mathrm{~cm}$. O'Shea (1996) menyebutkan bahwa famili Colubridae memiliki sisik ventralnya yang berkembang dengan baik, melebar sesuai dengan lebar perutnya. Kepala biasanya berbentuk oval dengan sisik-sisik yang tersusun dengan sistematis, memiliki tiga sisik besar diantara mata. Ekor umumnya silindris dan meruncing. Kebanyakan anggota famili Colubridae tidak berbisa atau berbisa namun tidak terlalu mematikan bagi manusia.

3. Famili Boidae

Candoia sp., memiliki warna tubuh ventral dan dorsal abu kecokelatan serta adanya variasi belang-belang putih pada bagian ventral kepala sampai ke bagian ekor. Kepala berbentuk segi tiga agak meruncing dan agak lonjong. Panjang tubuh dapat mencapai 1 meter.

Ciri khas ular Candoia sp. adalah hidung yang berbentuk kotak/balok, tidak berbisa dan tidak agresif. Biasanya hidup di dahan pepohonan, namun sering juga ditemukan di tanah. Aktif pada malam hari untuk mencari mangsa utamanya yaitu kadal kecil, cicak dan mamalia kecil. Posisi saat ditangkap melingkar di atas dahan pepohonan.

1. Famili Hylidae

Litoria infrafernata Guenther, 1867. Litoria infrafernata termasuk golongan katak pohon yang sangat umum dijumpai pada semua tipe habitat, baik hutan primer, sekunder, persawahan maupun pemukiman.

Memiliki mata bulat dengan pupil mata vetikal berwarna hitam kecokelatan. Bola mata cenderung besar, menonjol; iris hitam coklat. Bagian ventral tubuh berwarna hijau, sedangkan pada bagian bibir sampai ke dorsal berwarna putih kehijauan. Litoria infrafrenata umumnya bersuara sangat gaduh (jantan), dan mengumpul pada lahan berhutan, pemukiman dan atau bantaran sungai dimana terdapat genangan air, kubangan, kolam-kolam di pinggir jalan pada pemukiman. Panjang tubuh ratarata $31 \mathrm{~cm}$.

Litoria dan Nyctimystes yang hidup disepanjang 
sungai/perairan, 'memanggil' pasangan potensial untuk kawin dari bawah pohon atau semaksemak di atas air. Setelah melakukan perkawinan, betina akan bertelur dan akan meninggalkan telur di air hingga tahap berudu. Litoria berkembang biak di air yang tenang ataupun di air beriak kecil. Makanan utama Hylidae adalah serangga (Muller 2005).

2. Famili Ranidae

\section{a. Rana sp.}

Rana sp., memiliki warna tubuh pada bagian ventral hitam keabuabuan serta mengkilap dan berlendir, memiliki kepala yang besar, moncong sempit, mata besar, pupil mata berbentuk horizontal dan berada lebih ke arah belakang kepala. Pada bagian tibia dan femur berwarna putih bercak-bercak hitam. Pada bagian dorsal hitam keabu-abuan serta mengkilap dan berlendir. Panjang tubuh total mencapai $37 \mathrm{~cm}$.

Allison dalam Beehler dan Marshall (2007) menyebutkan bahwa katak New Guinea famili Ranidae saat ini diklasifikasi dalam tiga genus yang distribusinya luas di Indo-Pasifik (Rana, Platymantis dan Limnonectes). Di Papua tercatat terdapat sembilan jenis Rana, yang mana dua diantaranya merupakan endemik. Genus Platymantis memiliki 6 jenis terdapat di Papua, lima jenisnya adalah endemik. Limnonectes merupakan salah satu genus Rana yang diintroduksi dari luar (Pulau
Jawa dan Sumatera) oleh para transmigran.

b. Platymantis papuensis

Platymantis papuensis memiliki warna tubuh berwarna coklat dan terdapat sedikit bintik-bintik berwarna hitam. Bentuk mata besar, menonjol; iris hitam coklat, bola mata bulat, pupil mata vertikal berwarna hitam kecokelatan. Jenis ini pada saat dijumpai berada tepat di atas batu dan beberapa jenis yang sama juga ditemukan berada di atas lantai hutan pada serasah. Pada siang hari, jenis ini berlidung di dalam lubang-lubang batu, dan juga pada lubang pohon.

Di Pulau Mansinam jenis ini memiliki populasi yang sangat banyak, dan hampir ditemukan di setiap tempat, bahkan di areal pemukiman, jenis tersebut masih ditemukan. Secar umum panjang tubuh total mencapai $44 \mathrm{~cm}$.

Muller (2005) menyatakan bahwa genus Platymantis adalah terestrial dan semua jenisnya tidak tergantung pada air. Platymantis juga mengalami tahapan sama dengan Microhylidae dalam reproduksi, perkembangan langsung dari embrio (tidak melewati tahap berudu). Sedangkan genus Rana memiliki habitat di daerah sepanjang aliran sungai pada daerah dataran rendah hingga pada ketinggian 1.000 mdpl.

Penduduk Pulau Mansinam memiliki sebutan untuk spesies reptil dan ampibi yang terdapat di pulau tersebut. pada kelas amfibi spesies Litoria infrafrenata denngan sebutan kodok hijau, Rana 
sp.disebut kodok, Platymantis papuensis dengan sebutan kodok. Sedangakan untuk reptil, laticauda colubrina dengan sebutan ular moni-moni, Candoia sp. dengan sebutan ular malu-malu.

\section{DAFTAR PUSTAKA}

Allison A. 2007. Herpetofauna of Papua dalam Beehler, B. M and Marshall, A.The Ecology of Papua, Part One. Periplus Editions. Hong Kong. (Hal. 564-605).

Alonso JR, Arévalo R, Weruaga E, Porteros JG, Briñón JG, and Aijón J. 2000. Comparative and developmental neuroanatomical aspects of the NO system, in Functional Neuroanatomy of the Nitric Oxide System, eds H. W. M. Stein busch, J. Devente, and S. R. Vincent (Amsterdam: Elsevier), 51109.

BAPPENAS (Badan Perencanaan Pembangunan Nasional). 1993. Biodiversity action plan for Indonesia. Ministry of National Development Planning/National Development Planning Agency: Jakarta.

Conservation International. 2000. Teknik survei lapangan progam penilaian cepat (Rapid Assessmant Program).

Dumutu J. 2010. Keanekaragaman herpetofauna di Kampung Mandekman dan Rawahayu Distrik Ulilin Kabupaten Merauke. Skripsi Fakultas Matematika Dan Ilmu Pengetahuan Universitas Negeri Papua. (Tidak di terbitkan).

Gibbons JW, Scott DE, Ryan TJ, Buhlmann KA, Tuberville TD, Metts
BS, Greene JL, Mills T, Leiden Y, Poppy $\mathrm{S}$ and Winne CT. The global decline of reptiles, Déjà vu amphibians. Bioscience, 50 (8): 653666. https://doi.org/10.1641/00063568(2000)050[0653:TGDORD]2.0. $\mathrm{CO} ; 2$

Iskandar DT and Erdelen WR. 2006. Conservation of amphibians and reptiles Indonesia: issues and problems. Amphibian and Reptile Conservation, 4: 60-87.

Iskandar DT. 1998. Amfibi Jawa Bali Seri Panduan Lapang. Buku. Puslitbang Lembaga Ilmu Penelitian Indonesia. Bogor. 109 p.

Muller K. 2005. Keanekaragaman hayati papua. Wanggai. F, A. Sumule (editor); Penerjemah Ismoyo F, Kilmaskossu, A, Lumatauw, S, Nainggolan, N, Kilmaskossu M.St.E, Prawardani, S. Universitas Negeri Papua. Manokwari.

Obst FJ, K. Ritcher and U Jacob. 1988. Atlas of reptiles and amphibians for the Terrarium. T.F.H. Publications.inc. United State of America.

O'Shea M. 1996. A guide to the snake of Papua New Guinea. Independent Publishing. Port Moresby.

Stebbins RC and Cohen NW. 1997. A natural history of amphibians. New Jersey: Princeton Univ. Pr.

Yusuf LR. 2008. Studi keanekaragaman jenis reptil pada beberapa tipe habitat Di Eks-HPH PT. RKI Kabupaten Bungo Propinsi Jambi. Departemen Konservasi Sumberdaya Hutan Dan Ekowisata Fakultas Kehutanan Institut Pertanian Bogor. Bogor. 